\title{
Material modelling for creep-age forming of aluminium alloy 7B04
}

\author{
Aaron C.L. Lam ${ }^{1}$, Zhusheng Shi ${ }^{1, a}$, Xia Huang ${ }^{2}$, Yo-Lun Yang ${ }^{1}$, Yuansong Zeng ${ }^{2}$, and Jianguo Lin ${ }^{1}$ \\ ${ }^{1}$ Department of Mechanical Engineering, Imperial College London, London SW7 2AZ, UK \\ ${ }^{2}$ AVIC Beijing Aeronautical Manufacturing Technology Research Institute, Beijing 100024, PR China
}

\begin{abstract}
This paper presents a study on the creep-ageing behaviour of a peak-aged aluminium alloy $7 \mathrm{~B} 04$ under different tensile loads at $115^{\circ} \mathrm{C}$ and subsequently modelling it for creep-age forming (CAF) applications. Mechanical properties and microstructural evolutions of creep-aged specimens were investigated. The material was modelled using a set of unified constitutive equations, which not only captures the material's creep deformation but also takes into account yield strength contributions from solid solution hardening, age hardening and dislocation hardening during creep-ageing. A possible application of the present work is demonstrated by implementing the determined material model into a commercial finite element analysis solver via a user-defined subroutine for springback prediction of creep-age formed plates. A good agreement is observed between the simulated springback values and experimental results. This material model now enables further investigations of 7B04 under various CAF scenarios to be conducted inexpensively via computational modelling.
\end{abstract}

\section{Introduction}

Creep-age forming (CAF) is a metal forming technique that utilises the collective behaviour of viscoplastic deformation (creep) and microstructural change (ageing) of aluminium alloys under external loading at elevated temperature [1]. Manufacturing using this technique, in addition to better formed part quality and industrial environment, can reduce the number of manufacturing operations to form a part and thus the associated costs as well [2, 3]. As current deformation of a metallic alloy also depends on its microstructure, which changes dynamically during CAF, accurate prediction of formed part quality cannot be achieved solely using conventional viscoplastic creep equations. Attention has been drawn towards developing mechanism-based creep-ageing constitutive equations that consider evolutions of microstructure and mechanical properties, and efforts have been made towards the concurrent modelling of both the shaping and material processing functions of CAF as a result $[3,4]$.

In this work, the creep-ageing behaviour of a peak-aged aluminium alloy 7B04 is experimentally investigated and then modelled using a set of unified constitutive equations. The equation set was employed in finite element analysis to simulate an actual forming process of the alloy. Finally, a

\footnotetext{
${ }^{a}$ Corresponding author: Zhusheng. Shi@Imperial.ac.uk
}

This is an Open Access article distributed under the terms of the Creative Commons Attribution License 4.0, which permits unrestricted use, distribution, and reproduction in any medium, provided the original work is properly cited. 


\section{MATEC Web of Conferences}

Table 1. Chemical composition (wt\%) of 7B04.

\begin{tabular}{|c|c|c|c|c|c|c|c|c|c|}
\hline $\mathrm{Zn}$ & $\mathrm{Mg}$ & $\mathrm{Cu}$ & $\mathrm{Mn}$ & $\mathrm{Fe}$ & $\mathrm{Cr}$ & $\mathrm{Si}$ & $\mathrm{Ni}$ & $\mathrm{Ti}$ & $\mathrm{Al}$ \\
\hline 5.97 & 2.48 & 1.51 & 0.33 & 0.16 & 0.16 & 0.07 & $<0.05$ & $<0.05$ & Bal. \\
\hline
\end{tabular}

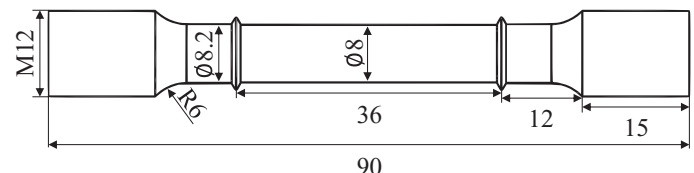

Figure 1. Geometry and key dimensions of the test piece (units in $\mathrm{mm}$ ).

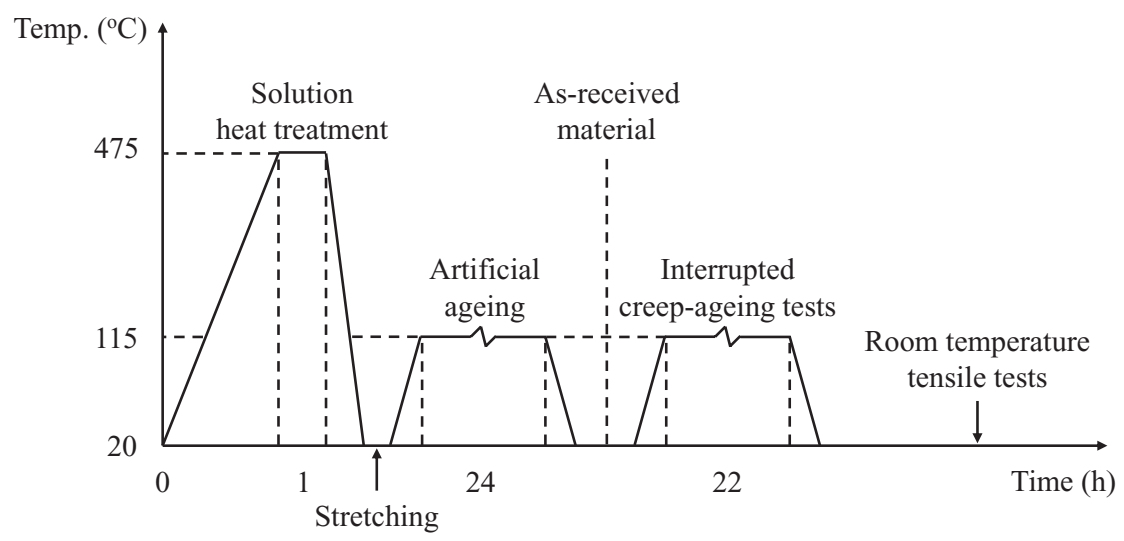

Figure 2. Heat treatment history of the material.

comparison is made between the simulated and experimentally measured springback values and the springback predictive ability using the material model is briefly discussed.

\section{Experimental details}

\subsection{Material}

The material used was aluminium alloy 7B04 whose chemical composition is presented in Table 1 . Creep-ageing tensile test pieces of geometry and dimensions shown in Fig. 1 and plates of dimensions $600 \mathrm{~mm} \times 350 \mathrm{~mm} \times 8.2 \mathrm{~mm}$ had been machined from the same bulk material in the longitudinal rolling orientation and provided in T651 temper by AVIC BAMTRI (Beijing, PR China).

\subsection{Material testing}

Figure 2 illustrates a schematic of the material's heat treatment cycle from solutionising to the subsequent material testing operations.

The creep-ageing test procedure used by Ho et al. [4] was adopted and the tests were carried out at $115^{\circ} \mathrm{C}$ under four tensile stress levels: 200, 240, 260 and $280 \mathrm{MPa}$. Room temperature tensile tests were carried out on selected creep-aged specimens. In addition, samples of the as-received material and those that had received a further $22 \mathrm{~h}$ stress-free ageing were analysed using transmission electron microscopy (TEM) to enable subsequent calibration of the alloy's precipitate growth. 


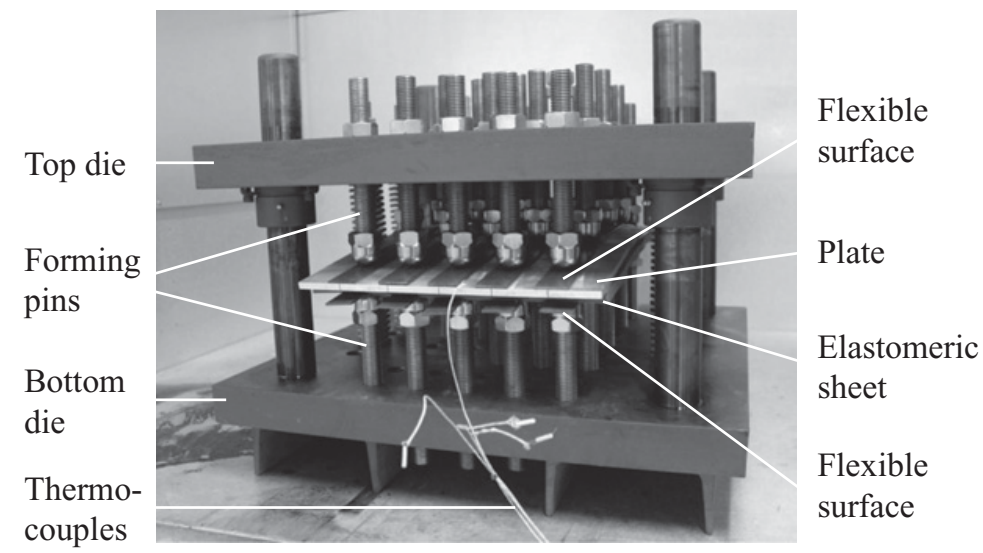

Figure 3. Experimental setup for the creep-age forming tests.

\subsection{Creep-age forming tests}

A novel flexible CAF tool was used for the CAF tests. The tooling setup, as shown in Fig. 3, comprised of twenty-five sparsely spaced forming pins on each side of the top and bottom dies. Flexible forming surfaces were on both sides of the plate with an additional elastomeric sheet layer between the plate and lower flexible surface. Further details of the CAF tool design and test setup can be found in [5]. The main steps of the forming test include: (I) Setup the forming tool surface by adjusting the heights of forming pins; (II) Load the top die to deform the plate to the required shape; (III) Lock the top and bottom dies using nuts and bolts; (IV) Run the creep-ageing thermal cycle; (V) Release the load by loosening the nuts whilst springback occurs.

CAF tests were carried out on two plates at a single curvature bending radius of $1200 \mathrm{~mm}$. After unloading, profiles of the unloaded plates were measured and springback of the plates $(S)$ were calculated using $\left.S=1-\left(\delta_{f} / \delta_{l}\right)\right)$, where $\delta_{f}$ and $\delta_{l}$ are the final and loaded centre deflections of each plate respectively. Repeated deflection measurements were obtained from each side of the formed plates and the final average value was taken.

\section{Material modelling}

\subsection{Unified creep-ageing constitutive equations}

7B04 is an age-hardenable aluminium alloy. During ageing of 7000 series aluminium alloys, microstructure evolves from supersaturated solid solution and precipitation occurs in the following sequence $[6,7]:$ Solid solution $\rightarrow$ GP zones $\rightarrow \eta^{\prime} \rightarrow \eta\left(\mathrm{MgZn}_{2}\right)$.

The strength of the alloy changes as precipitation takes places. At the early stage, GP zones form and the yield strength increases as precipitates nucleate and grow. GP zones are then gradually replaced by semi-coherent $\eta^{\prime}$ until a peak-age condition is reached. This is when the alloy attains its peak strength with an optimal precipitate size and density (spacing) combination. Afterwards, $\eta^{\prime}$ are replaced by incoherent and stable $\eta$ whilst precipitates coarsen, leading to a gradual decrease in strength (over-ageing). Throughout this process, contribution from solid solution hardening gradually decreases. During creep-ageing, dislocation hardening also contributes to the overall strength of the material, especially in the early stage. 
In order for the described behaviour of 7B04 to be modelled, the multiaxial unified constitutive equations proposed by Zhan et al. [8] were adapted:

$$
\begin{gathered}
\dot{\varepsilon}_{e}^{c r}=A_{1} \sinh \left\{B_{1}\left[\sigma_{e}\left(1-\bar{\rho}_{d}\right)-k_{\epsilon c} \sigma_{y}\right]\right\} \\
\dot{\sigma}_{a g e}=C_{a} \dot{\bar{r}}_{p}^{m_{1}}\left(1-\bar{r}_{p}\right) \\
\dot{\sigma}_{s o l}=-C_{s} \dot{\bar{r}}_{p}^{m_{2}}\left|\bar{r}_{p}-1\right| \\
\dot{\sigma}_{d i s}=-A_{2} \cdot n_{d} \cdot \bar{\rho}_{d}^{n d-1} \dot{\bar{\rho}}_{d} \\
\sigma_{y}=\sigma_{s o l}+{\sqrt{\sigma_{a g e}^{2}+\sigma_{d i s}^{2}}}_{\dot{\bar{r}}_{p}=C_{r}\left(Q_{r}-\bar{r}_{p}\right)^{m_{3}}\left(1+\gamma_{r} \bar{\rho}_{d}^{m_{4}}\right)} \\
\dot{\bar{\rho}}_{d}=A_{3}\left(1-\bar{\rho}_{d}\right) \dot{\varepsilon}_{e}^{c r}-C_{\rho} \bar{\rho}_{d}^{m s}
\end{gathered}
$$

where $A_{1}, B_{1}, k_{\varepsilon c}, C_{a}, m_{1}, C_{s}, m_{2}, A_{2}, n_{d}, C_{r}, Q_{r}, m_{3}, \gamma_{r}, m_{4}, A_{3}, C_{\rho}, m_{5}$ are material constants. These equations describe the inter-relationship amongst the equivalent stress $\left(\sigma_{e}\right)$, normalised dislocation density $\left(\bar{\rho}_{d}\right)$, normalised precipitate size $\left(\bar{r}_{p}\right)$ and effective creep strain $\left(\varepsilon_{e}^{c r}\right)$, as well as the strength contributions from solid solution hardening $\left(\sigma_{\text {sol }}\right)$, age hardening $\left(\sigma_{\text {age }}\right)$ and dislocation hardening $\left(\sigma_{\text {dis }}\right)$. Eq. (1) describes the rate of creep strain accumulation, which is not only a function of stress but also of dislocation density and yield strength $\left(\sigma_{y}\right)$. Readers are referred to [8] for detailed descriptions of Eqs. (1)-(7).

\subsection{Determination of initial conditions and material constants}

An evolutionary algorithm based optimisation software developed by Zhang et al. [9] was used for material constants determination. The alloy's yield strength evolutions and creep-ageing curves obtained from the tensile creep-ageing tests were used for model calibration. This was coupled with manual constants adjustments carried out in MATLAB to calibrate for the TEM analysis result.

Table 2 presents the initial conditions used and material constants determined. Referring to the initial conditions, the as-quenched yield strength of $7 \mathrm{~B} 04$ was $206 \mathrm{MPa}$ [10]. A value of $\sigma_{\text {sol }}^{0}=190 \mathrm{MPa}$ was chosen for the as-recieved T651 condition. Before any creep-ageing takes place, $\sigma_{\text {age }}^{0}=\sigma_{y}^{0}-\sigma_{\text {sol }}^{0}$, where $\sigma_{y}^{0}=537 \mathrm{MPa}$ was obtained from the tensile tests. $\bar{r}_{p}^{0}=1$ was set as the material is at its peakaged condition. The initial normalised dislocation density is significantly smaller than the maximum dislocation density and $\bar{\rho}_{d}^{0}=1 E-5$ was used.

Figure 4 illustrates a comparison for each of the calibrated creep-ageing curves and yield strength evolutions with the corresponding experimental data. After $22 \mathrm{~h}$ of creep-ageing, maximum deviations of $0.29 \mathrm{~m} \varepsilon$ and $9.35 \mathrm{MPa}$ are observed which represent a 5.6 and $1.8 \%$ difference respectively. Thus, characteristics of both the viscoplastic deformation and yield strength evolution of 7B04-T651 during creep-ageing have been captured with close agreements. 


\section{ICNFT 2015}

Table 2. The initial conditions used and material constants determined for CAF of 7B04-T651 $\left(115^{\circ} \mathrm{C}, 22 \mathrm{~h}\right)$.

\begin{tabular}{|c|c|c|c|c|}
\hline \multicolumn{5}{|c|}{ Initial conditions } \\
\hline$\sigma_{\text {sol }}^{0}(\mathrm{MPa})$ & $\sigma_{\text {age }}^{0}(\mathrm{MPa})$ & $\sigma_{y}^{0}(\mathrm{MPa})$ & $\bar{r}_{p}^{0}$ & $\bar{\rho}_{d}^{0}$ \\
\hline 190 & 347 & 537 & 1 & $1 \mathrm{E}-5$ \\
\hline
\end{tabular}

CAF material constants

\begin{tabular}{|c|c|c|c|c|c|c|c|c|}
\hline$A_{1}\left(\mathrm{~h}^{-1}\right)$ & $B_{1}\left(\mathrm{MPa}^{-1}\right)$ & $k_{\varepsilon c}$ & $C_{a}(\mathrm{MPa})$ & $m_{1}$ & $C_{s}(\mathrm{MPa})$ & $m_{2}$ & $A_{2}(\mathrm{MPa})$ & $n_{d}$ \\
\hline $1.95 \mathrm{E}-6$ & 0.042 & 0.16 & 4 & 0.9 & 0.2 & 0.45 & 260 & 0.7 \\
\hline$C_{r}\left(\mathrm{~h}^{-1}\right)$ & $Q_{r}$ & $m_{3}$ & $\gamma_{r}$ & $m_{4}$ & $A_{3}$ & $C_{\rho}\left(\mathrm{h}^{-1}\right)$ & $m_{5}$ & \\
\hline 0.098 & 1.8 & 2.2 & 3 & 2 & 150 & 0.145 & 1.5 & \\
\hline
\end{tabular}

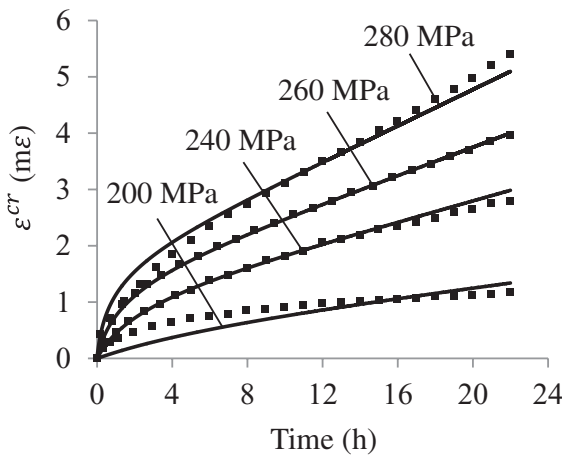

(a)

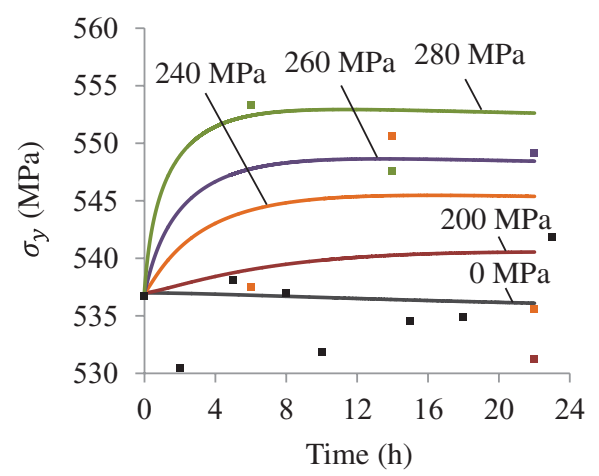

(b)

Figure 4. Comparisons of the experimentally obtained (symbols) and calibrated (solid lines) (a) creep-ageing curves and (b) yield strength evolutions for creep-ageing at $115^{\circ} \mathrm{C}$ under the indicated stress levels.

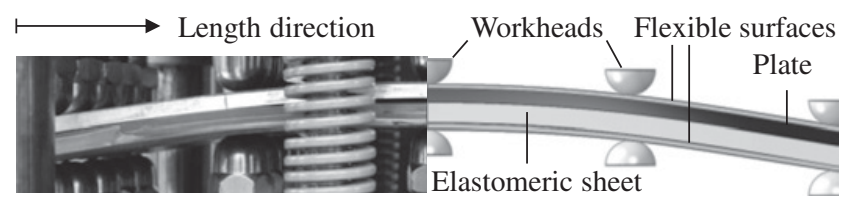

(a)

(b)

Figure 5. Side-view images taken at full loading of (a) a physical forming test and (b) finite element simulation with to-scale rendering of shell thicknesses.

In addition to the creep and strength evolutions, the alloy's precipitate growth was also calibrated. This was based on the TEM analysis result which estimated an average growth in precipitate size from 8.5 to $12.6 \mathrm{~nm}$ after $22 \mathrm{~h}$ of stress-free ageing.

\section{Application to springback prediction}

\subsection{Finite element model}

A quarter finite element (FE) model of the flexible CAF tool was constructed in Abaqus. As shown in Fig. 5, only workheads of the forming pins were modelled. Detailed descriptions of the FE model and modelling procedure are available in [5]. 


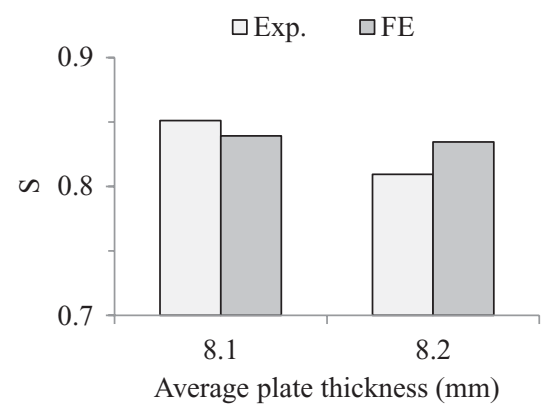

Figure 6. Comparisons of the experimentally measured and simulated springback of 7B04-T651 plates. The forming tests were conducted at a single curvature bending radius of $1200 \mathrm{~mm}$ under $115^{\circ} \mathrm{C}$ for $22 \mathrm{~h}$.

The plates were modelled using initially flat shell elements with their actual plate thicknesses, a Young's modulus of $67 \mathrm{GPa}$ and a Poisson's ratio of 0.33 assigned. Equations (1)-(7) were implemented into Abaqus via the user-defined subroutine CREEP with the initial conditions and material constants in Table 2 assigned. The following six-step modelling procedure was employed: (I) Initiate the simulation with temperature, boundary conditions and contact scheme defined; (II) Load the upper workheads to deform the plate whilst the lower workheads remain fixed; (III) Heat the entire configuration up to the CAF temperature; (IV) Propagate into a visco step for creep-ageing to take place; (V) Cool the entire configuration down to room temperature; (VI) Revert the upper workheads to allow springback occurs.

Simulation of the CAF tests was carried out using the FE model under conditions that match those of the forming tests. Springback of the plates was modelled, calculated and compared with those of the formed plates.

\subsection{Springback comparison}

Figure 6 illustrates the comparisons between the measured and FE-simulated springback values. They both show a decrease in springback as the plate thickness increases from 8.1 to $8.2 \mathrm{~mm}$. The FEsimulated springback values deviate slightly from the experimental values but they are within an acceptable range of -1.2 and $+2.5 \%$ difference in springback or +0.3 and $-0.6 \mathrm{~mm}$ difference in vertical deflection. Thus, a good prediction of springback was achieved using this material model.

\section{Summary}

A material model was presented with its constants determined for creep-age forming of aluminium alloy 7B04-T651. In addition to viscoplastic deformation, the model also predicts the precipitate growth and yield strength evolution of the alloy. A possible application was demonstrated where springback of creep-age formed 7B04-T651 plates was predicted to within a close range of $2.5 \%$ of experimental results. The findings summarised in this paper enable creep-age forming of the alloy, under various initial and boundary conditions, to be investigated inexpensively via computational modelling.

The strong support from Aviation Industry Corporation of China (AVIC) Beijing Aeronautical Manufacturing Technology Research Institute (BAMTRI) for this funded research is much appreciated. The research was performed at the AVIC Centre for Structural Design and Manufacture at Imperial College London. 


\section{ICNFT 2015}

\section{References}

[1] M.C. Holman, J. Mech. Work. Technol. 20, 477 (1989)

[2] F. Eberl, S. Gardiner, G. Campanile, G. Surdon, M. Venmans, P. Prangnell, J. Aerospace Eng. 222, 873 (2008)

[3] L. Zhan, J. Lin, T.A. Dean, Int. J. Mach. Tool. Manu. 51, 1 (2011)

[4] K.C. Ho, J. Lin, T.A. Dean, J. Mater. Process. Technol. 153-154, 122 (2004)

[5] A.C.L. Lam, Imperial College London, $\mathrm{PhD}$ thesis (to be deposited)

[6] R. Ferragut, A. Somoza, A. Tolley, Acta Mater. 47, 4355 (1999)

[7] G. Sha, A. Cerezo, Acta Mater. 52, 4503 (2004)

[8] L. Zhan, J. Lin, T.A. Dean, M. Huang, Int. J. Mech. Sci. 53, 595 (2011)

[9] P. Zhang, J. Lin, D. Balint, Imperial College London, Project report (2012)

[10] Z. Li, B. Xiong, Y. Zhang, B. Zhu, F. Wang, H. Liu, Trans. Nonferrous Met. Soc. China, 18, 40 (2008) 